\title{
Blunt carotid artery injury after minor facial trauma
}

\author{
Amera Murabit MD ${ }^{1}$, Edward E Tredget MD MSc FRCSC ${ }^{1,2}$
}

\author{
A Murabit, EE Tredget. Blunt carotid artery injury after minor \\ facial trauma. Can J Plast Surg 2012;20(3):194-196.
}

A healthy young man presented three days after suffering a punch to the face resulting in minimally displaced mandibular fractures. History revealed an episode of anterograde amnesia and a delayed episode of dysphonia. Apart from the fractured mandible, the physical examination was otherwise noncontributory. Imaging revealed severe luminal narrowing of the left cervical internal carotid artery distal to the carotid bifurcation, consistent with carotid dissection; and two focal hypodensities in the left frontal and parietal cortices, highly suggestive of acute secondary embolic infarcts. The patient was treated with systemic anticoagulation for three months and experienced no further neurological symptoms. His mandibular fractures, treated conservatively, healed without any complications.

Blunt carotid artery injuries are uncommon and diverse. Neurological symptoms may develop in a delayed fashion, thus, a high index of suspicion based on knowledge of the injury mechanisms and patterns of associated injuries may enable earlier diagnosis and treatment. Angiographic imaging is essential for the diagnosis and classification of injury characteristics (eg, type, location, etc). Treatment must be considered on an individual patient basis depending on the presentation, grade and morphology of the lesion. Although no level I clinical trials exist on the topic, anticoagulation seems to be the treatment of choice in most cases and surgical intervention is not commonly indicated. Carotid artery dissection without complete thrombosis may be effectively treated with systemic anticoagulation or antiplatelet therapy in the majority of cases.

Key Words: Blunt trauma; Carotid artery dissection; Carotid artery injury; Facial trauma

$\Delta$ healthy 22-year-old man presented to a trauma hospital emerAgency department for plastic surgical consultation, assessment and definitive management of facial fractures. An initial assessment was performed and a diagnosis of mandibular fractures was made in a peripheral hospital the day before.

Three days before, the patient was involved in a physical altercation while drunk and suffered a single punch to the left side of his face. He reported a brief episode of anterograde amnesia (approximately $1 \mathrm{~min}$ ), after which his memory was completely normal. Afterward, he drove home (more than $5 \mathrm{~h}$ away) and went to sleep. His girlfriend woke him a couple of hours later, and at that time, the patient found himself unable to speak properly (ie, slurring his speech); this episode lasted $30 \mathrm{~min}$ to $45 \mathrm{~min}$. He then presented to a rural emergency department where a diagnosis of mandibular fracture was made, and he was then referred to the regional trauma hospital. At the time of presentation, he denied use of any substances besides the aforementioned alcohol.

On examination, he was found to be stable, in no distress, alert, oriented and appropriate. Head and neck examinations revealed no tenderness, unrestricted extraocular movements, no palpable bony step deformity, a stable midface and a normal cranial nerve examination (cranial nerves II to XII). There were two superficial abrasions to his right temple. Mandibular examination revealed minimal generalized swelling, tenderness at left angle and right parasymphyseal

\section{Une lésion carotidienne fermée après un traumatisme facial mineur}

Un jeune homme en santé a consulté trois jours après avoir subi un coup à la figure ayant suscité des fractures mandibulaires peu déplacées. Les antécédents ont révélé un épisode d'amnésie antérograde et un épisode tardif de dysphonie. À part la fracture de la mandibule, l'examen physique n'a rien révélé. L'imagerie a établi un important rétrécissement intracavitaire de la carotide cervicale gauche interne dans la région distale de la bifurcation carotidienne, évocatrice d'une dissection carotidienne, ainsi que deux hypodensités focales dans les cortex pariétal et frontal gauche, hautement évocatrices d'infarctus emboliques secondaires aigus. Le patient a reçu des anticoagulants systémiques pendant trois mois et n'a souffert d'aucuns autres symptômes neurologiques. Ses fractures mandibulaires, traitées de manière classique, ont guéri sans complication.

Les lésions carotidiennes fermées sont peu courantes et diversifiées. Des symptômes neurologiques peuvent se manifester tardivement. Ainsi, un fort indice de présomption fondé sur la connaissance des mécanismes de la lésion et des modes de lésions connexes peuvent favoriser un diagnostic et un traitement plus rapides. L'angiographie est essentielle pour poser le diagnostic et classer les caractéristiques de la lésion (p. ex., lieu, foyer, etc.) Le traitement dépend de chaque patient compte tenu de la présentation, du grade et de la morphologie de la lésion. Même s'il n'existe aucun essai clinique de niveau I sur le sujet, les anticoagulants semblent constituer le traitement de première intention dans la plupart des cas. L'intervention chirurgicale est rarement indiquée. Dans la majorité des cas, la dissection carotidienne sans thrombose complète peut être traitée avec succès par des anticoagulants systémiques ou des antiplaquettaires.

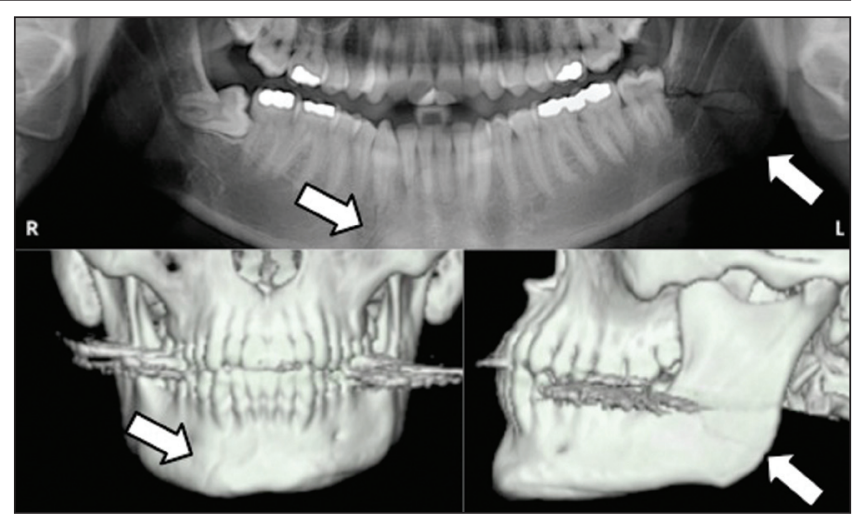

Figure 1) Arrows on facial bone imaging (panogram [top] and computed tomography [bottom]) revealing very minimally displaced left angle and right parasymphyseal fractures

regions, no palpable bony step deformity, no trismus, no hematoma, no intraoral lacerations or appreciable intraoral communication, and normal objective occlusion. Facial bone imaging (panogram and computed tomography $[\mathrm{CT}]$ ) revealed very minimally displaced left angle and right parasymphyseal fractures (Figure 1).

${ }^{1}$ Division of Plastic and Reconstructive Surgery; ${ }^{2}$ Division of Critical Care, Department of Surgery, University of Alberta, Edmonton, Alberta

Correspondence: Dr Edward E Tredget, 2D2.28 Walter C Mackenzie Health Sciences Centre, University of Alberta, 8440-112 Street,

Edmonton, Alberta T6G 2B7. Telephone 780-407-6979, fax 780-407-7394, e-mail etredget@ualberta.ca 


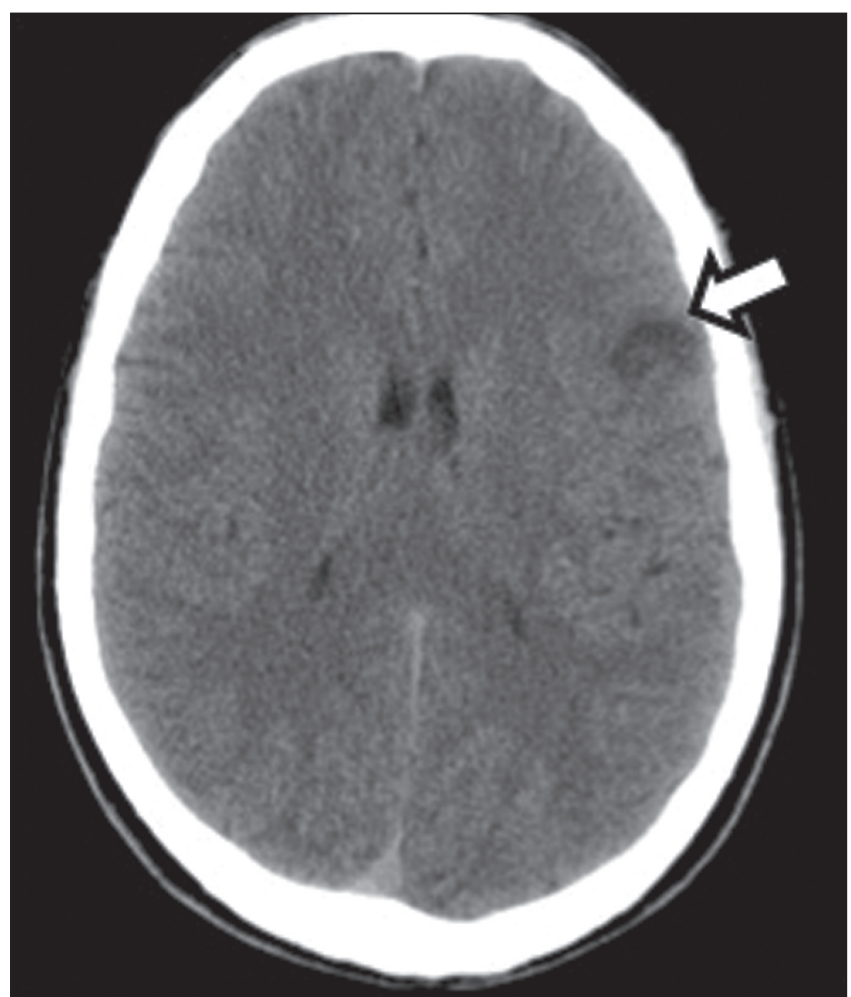

Figure 2) Computed tomography head scan demonstrating two focal hypodensities (arrow) in the left frontal and parietal cortexes, highly suggestive of acute secondary embolic infarcts

Given the history of slurred speech and a high index of suspicion, a CT head scan was ordered, which showed left carotid artery dissection and two focal hypodensities in the left frontal and parietal cortexes, which were highly suggestive of acute secondary embolic infarcts (Figure 2). The stroke neurology team was consulted, and a CT-angiogram was performed revealing severe luminal narrowing of the left cervical internal carotid artery distal to the carotid bifurcation, over a length of $5 \mathrm{~cm}$, consistent with carotid dissection (Figure 3 ).

A diagnosis of traumatic left internal carotid artery dissection with two cortical infarcts was established. Given that the patient's symptoms had completely resolved and that his neurological examination was completely normal, the stroke neurology team suggested anticoagulation for three months. Acetylsalicylic acid $325 \mathrm{mg}$ was given in the hospital, followed by $81 \mathrm{mg}$ daily. Also a repeat CT-angiogram at three months, to rule out a pseudoaneurysm, and no alcohol for one month was suggested. Any further episodes were to be reported to the stroke neurology team.

Regarding his fractured mandible, initial options included maxillomandibular-fixation for two to three weeks, or conservative treatment with a soft diet for six weeks. Ultimately, given his secondary diagnosis, he was treated with the latter option. The patient was discharged home with instructions for a soft diet for six weeks and prescriptions for oral antibiotics, oral analgesics and acetylsalicylic acid (81 mg daily). Follow-up was arranged with the plastic surgery and stroke neurology teams. The patient experienced no further neurological symptoms, and his mandibular fractures healed without any complications.

\section{DISCUSSION}

Blunt carotid artery injuries are rare, and are estimated to constitute less than $3 \%$ of all carotid artery trauma (1). The detected incidence of blunt carotid artery injury is reportedly $0.08 \%$ to $0.67 \%$ in blunt trauma patients (1-4), with motor vehicle accidents being the most common cause. Fistfights, falls, strangulation, chiropractic manipulation, carotid artery compression and local surgical procedures have all been reported as causes $(2,5)$. Specific patterns of injury associated with blunt carotid injury have been identified. Suggested triggers for the

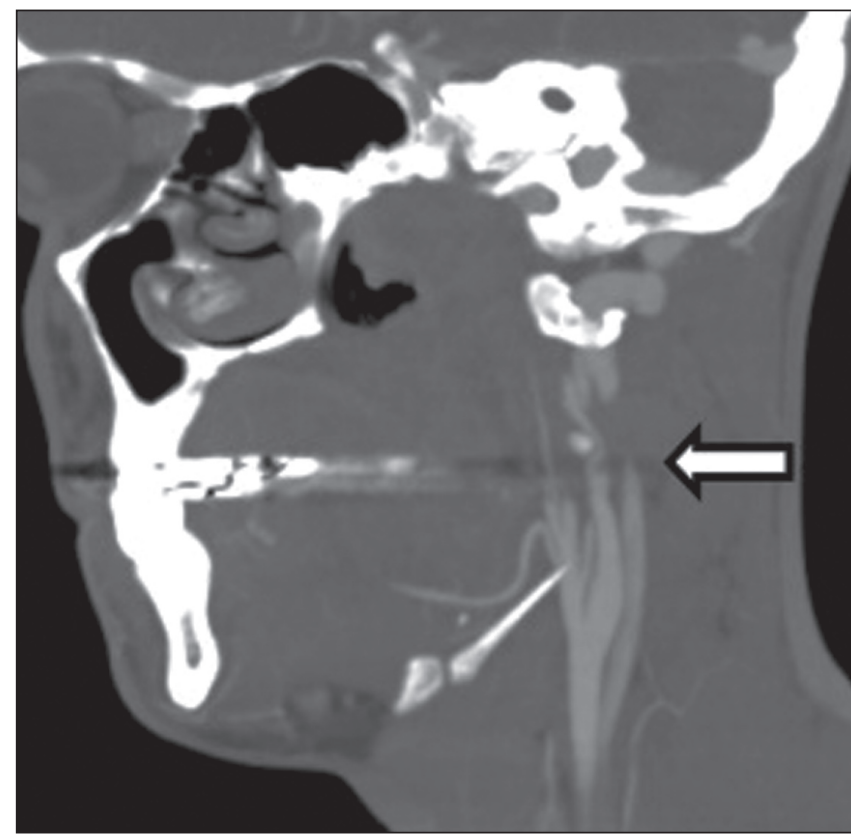

Figure 3) Computed tomography angiogram demonstrating severe luminal narrowing of the left cervical internal carotid artery (arrow) distal to the carotid bifurcation, over a length of $5 \mathrm{~cm}$, consistent with carotid dissection

screening of blunt carotid injury include trauma patients presenting with cervical spine fracture, Horner's syndrome, Le Fort facial fractures, skull base fractures involving foramen lacerum, neck soft-tissue injury, and/or patients with a Glasgow Coma Score $\leq 8$ and thoracic injury, or a Glasgow Coma Score $\leq 8$ and facial fractures (4).

Carotid artery injury can easily be missed on initial examination. The diagnosis of carotid artery injury may be further obscured by associated injuries, scant clinical findings and normal initial CT results. Early diagnosis, facilitated by an awareness of the causes and mechanisms of blunt vessel injury, is the most important determinant of a good outcome. Conventional carotid angiography is considered the gold standard for diagnosis of blunt carotid artery injury (4); however, CT angiograms and magnetic resonance angiograms are also useful diagnostic tools.

To date, there have been no randomized controlled trials to establish optimum management of blunt carotid artery injury. Currently, available treatment modalities are anticoagulation, antiplatelet therapy, open surgery and, more recently, endovascular treatments (4). A multicentre retrospective analysis suggested that because the extent of the initial disruption may be underestimated by the available imaging modalities, anticoagulation or antiplatelet therapy should be instituted for all nonocclusive carotid arterial dissections regardless of the degree of luminal narrowing (1). Prevention of arterial thrombosis and embolization is the rationale for administration of systemic anticoagulation in the treatment of internal carotid artery dissection without arterial occlusion (1).

\section{KEY POINTS}

1. Blunt carotid artery injuries are uncommon and diverse.

2. Neurological symptoms may develop in a delayed fashion, thus, a high index of suspicion based on knowledge of the injury mechanisms and patterns of associated injuries may enable earlier diagnosis and treatment.

3. Angiographic imaging is essential for the diagnosis and classification of injury characteristics (eg, type, location, etc).

4. Treatment must be considered on an individual patient basis depending on the presentation, grade and morphology of the lesion. Although no level I clinical trials exist, anticoagulation seems to be 
the treatment of choice in most cases and surgical intervention is not commonly indicated.

5. Carotid artery dissection without complete thrombosis may be effectively treated with systemic anticoagulation or antiplatelet therapy in the majority of cases.

\section{REFERENCES}

1. Cogbill TH, Moore EE, Meissner M, et al. The spectrum of blunt injury to the carotid artery: A multicenter perspective. J Trauma 1994;37:473-9.
2. Davis JW, Holbrook TL, Hoyt DB, Mackersie RC, Field TO Jr, Shackford SR. Blunt carotid artery dissection: Incidence, associated injuries, screening, and treatment. J Trauma 1990;30:1514-7.

3. Fabian TC, Patton JH, Croce MA, Minard G, Kudsk KA, Pritchard FE. Blunt carotid injury: Importance of early diagnosis and anticoagulant therapy. Ann Surg 1996;223:513-25.

4. Singh RR, Barry MC, Ireland A, Bouchier Hayes D. Current diagnosis and management of blunt internal carotid artery injury. Eur J Vasc Endovasc Surg 2004;27:577-84.

5. Opeskin K. Traumatic carotid artery dissection. Am J Forensic Med Pathol 1997;18:251-7. 